\title{
Thermal efficiency of the building envelope with the air layer and reflective coatings
}

\author{
Adam Ujma ${ }^{1, *}$, and Nina Umnyakova ${ }^{2}$ \\ ${ }^{1}$ Czestochowa University of Technology, Faculty of Civil Engineering, ul. Akademicka 3, \\ 42-200 Czestochowa, Poland \\ ${ }^{2}$ Research Institute of Building Physics of the Russian Academy of Architecture and Building \\ Sciences (NIISF RAASN), 127238, Moscow, Lokomotivnyj pr. 21, Russia
}

\begin{abstract}
Currently, when calculating the heat-shielding qualities of external enclosing structures, the ability of fencing surfaces to reflect the heat flux by radiation is not taken into account. All this leads to an underestimation of heat-shielding characteristics in comparison with reality. Studies have shown. that a number of factors affect the thermal protection of air layers - the difference in temperature on the surfaces of the interlayer, its thickness. But the most important is the coefficient of elimination of the air gap surface. The use of reflective heat insulation with a low emissivity on one of the surfaces of the air gap makes it possible to increase its thermal protection 2.5-3 times. The article presents the calculations of thermal protection of air gaps with different emissivity coefficients of surfaces and conclusions about the effectiveness of the use of reflective insulation.
\end{abstract}

\section{Introduction}

Currently, the market all over world has a wide range of various effective insulation building materials based on mineral wool, polystyrene foam and others. Their thermal insulation properties depend on the thermal conductivity of the material. With an increasing in the thickness of the insulation, the heat flux passing through this heat-insulating material decreases. However, only the coefficient $\lambda$ is taken into account in the calculations, and the ability of materials surfaces to reflect the flow of heat is nowhere taken into account. Moreover the industry in many countries produces innovative materials with reflective thermal properties.

The principle of operation of innovative heat-insulating materials with reflective film from aluminum foil is based on the ability of a shiny surface with a low emissivity to reflect the radiant component of the heat flux. For this reason, the effectiveness of reflective insulation does not depend on the thickness of the material, but only on the emission of the surface. In this case, it is necessary to have an air gap at the reflective surface, through which the radiant component of the heat flux passes. The combination of reflective insulation with heat-insulating material, for example, polyethylene foam, allows to obtain a qualitatively new product with high heat-shielding qualities.

*Corresponding author: aujma55@,wp.pl 
The analysis of thermal insulation capacity of such materials, applied in specific building structures, is undertaken, among others, by the papers [1-4]. These studies indicate that such materials show positive effects with regard to improvement of thermal insulation capacity of external envelopes wall and other constructions..

However, the widespread introduction of such materials into building practice presents great difficulties. Firstly, standard methods for assessing heat-shielding qualities are not suitable for them and it is necessary to develop new methods or modify existing ones, which requires both time and money. In addition, existing calculation methods are not always applicable to innovative materials. In particular, when using materials with reflective insulation, standard calculation methods do not take into account the reflection of the radiant component of the heat flux. As a result, at the stage of choosing materials, designers are not able to correctly assess the actual thermal protection of an innovative material or structure with these materials and correctly arrange it in the building envelope.

Conducted in NIISF RAACS (Russia) studies of reflective insulation made it possible to evaluate the effectiveness of its use. Experimental studies of closed air gaps with reflective thermal insulation and without it have shown that the presence of a shine reflective material on one of the surfaces of the air layer allows to increase its thermal resistance in 2.5-3 times. A method was developed for calculating the thermal resistance of closed air spaces with reflective thermal insulation, taking into account the multiple reflection of the radiant heat flux from its internal surfaces. Thermo-technical calculations of a multilayer wall with air gaps of various thickness in the presence of reflective insulation were carried out. The obtained theoretical and experimental studies have shown good convergence of the results.

\section{The method of determining thermal parameters of the air layer}

According to the standard [5], heat resistance of an unventilated air space $R_{g}$, with a length and width higher than the 10 -fold thickness, is expressed by the following relation:

$$
R_{g}=\frac{1}{h_{a}+h_{r}}
$$

where:

$h_{a}-$ is the convective/conduction heat transfer coefficient, $\mathrm{W} /\left(\mathrm{m}^{2} \mathrm{~K}\right)$

$h_{r}$ - is the radiation heat transfer coefficient, $\mathrm{W} /\left(\mathrm{m}^{2} \mathrm{~K}\right)$.

The value of the convective heat transfer coefficient $h_{a}$ is assumed on the basis of parameters (Table 1).

Table 1. Value of the convective/conduction heat transfer coefficient $h_{a}$ depending on the temperature difference on the air layer surfaces $\Delta T$, based on the standard [5].

\begin{tabular}{|c|c|c|}
\hline \multirow{2}{*}{$\begin{array}{l}\text { Direction } \\
\text { of heat flow }\end{array}$} & $\Delta T \leq 5 \mathrm{~K}$ & $\Delta T>5 \mathrm{~K}$ \\
\hline & \multicolumn{2}{|c|}{$\mathbf{W} /\left(\mathbf{m}^{2} \mathbf{K}\right)$} \\
\hline horizontal & 1.25 & $0.73 \cdot \Delta T^{1 / 3}$ \\
\hline upwards & 1.95 & $1.14 \cdot \Delta T^{1 / 3}$ \\
\hline downwards & $0.12 \cdot d^{-0.44}$ & $0.09 \cdot \Delta T^{0.187} \cdot d^{-0.4}$ \\
\hline
\end{tabular}

According to the given data, the coefficient $h_{a}$ only depends on the air layer thickness in case of a horizontal envelope, at a downward heat flow. Only for a temperature difference 
$\Delta T$ higher than $5 \mathrm{~K}$, the coefficient $h_{a}$ also depends on $\Delta T$. This seems to be a major simplification since, according to the research data presented in Table 1, the intensity of conductive and convective heat exchange in an unventilated air layer depends on both the layer thickness $d$ and the temperature difference on the surfaces thereof.

The data presented in the paper [6] show that the effect of the width of an air gap and the temperature difference at the limits of the air layer is significant. Even at a low temperature difference, the change of layer thickness from $2 \mathrm{~cm}$ to $5 \mathrm{~cm}$ causes the coefficient $\lambda_{\lambda}+\lambda_{a}$ to nearly double.

\section{Heat transfer parameters in air spaces}

The chart (Fig. 1) compares the heat transfer coefficient values, calculated on the basis of data from the studies [7-10], with values resulting from the standard parameters [5].

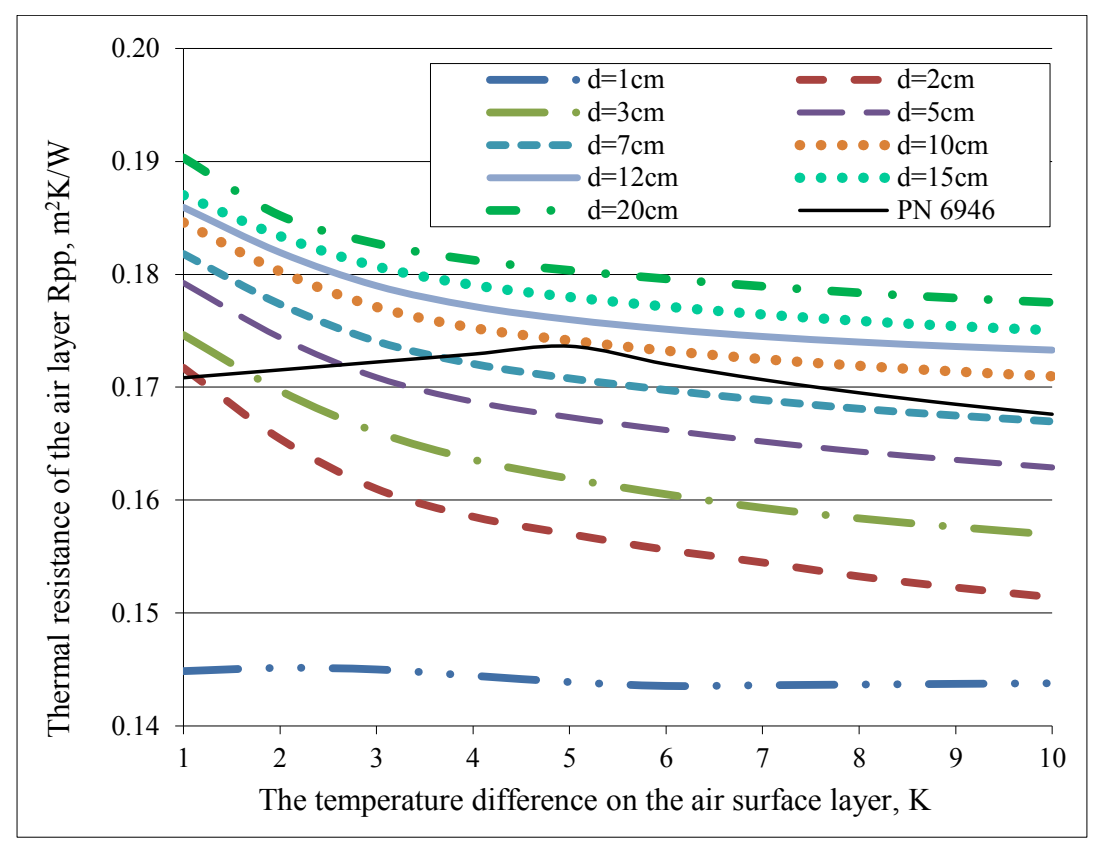

Fig.1. The nature of the change of value of the conductive and convective heat transfer coefficient depending on the temperature difference at the limits of the air layer and its thickness.

As the comparison of calculation results (Fig. 1) shows, the values given by the standard parameters overlap with the data of calculations for air layer thickness in the order of $7-10 \mathrm{~cm}$, at a temperature difference above $5 \mathrm{~K}$.

The standard parameters [5] give a constant value of the coefficient $h_{a}$ with regard to the temperature difference $\Delta T<5 \mathrm{~K}$, disregarding the fact that the value of the coefficient $h_{a}$ largely depends on the air layer thickness and the temperature difference $\Delta T$.

In general, it can be stated that for air layer thickness lower than $7 \mathrm{~cm}$, standard values are understated, and for thickness higher than $10 \mathrm{~cm}$, they are overstated.

The value of the radiation heat transfer coefficient $h_{r}$, in accordance with the standard parameters [5], is determined on the basis of the relation: 
where:

$$
h_{r}=E \cdot h_{r 0}
$$

$E$ - is the surface emittance, emissivity parallel surface, -

$$
E=\varepsilon_{1-2}
$$

$h_{r 0}$ is the radiation coefficient for a black-body surface, $\mathrm{W} /\left(\mathrm{m}^{2} \mathrm{~K}\right)$

$$
h_{0}=4 \cdot \sigma \cdot T_{m}^{3}
$$

$\sigma-$ is the Stefan-Boltzmann constant, $5.67 \cdot 10^{-8} \mathrm{~W} /\left(\mathrm{m}^{2} \mathrm{~K}^{4}\right)$

$T_{m}$ - is the average temperature of the emitting surface and its surroundings, $\mathrm{K}$

The standard [5] lacks instructions concerning how the temperature at the surfaces limiting the air layer can be included in the calculations. The explanations mention $T_{m}$ as the average temperature of the surface and its environment. Therefore, it can be assumed as the average temperature of both surfaces of the air layer.

The radiation heat transfer coefficient $h_{r(1-2)}$ between the surfaces limiting the air layer may be derived from the relation below:

$$
h_{r(1-2)}=\frac{C_{1-2}\left[\left(\frac{\theta_{1}+273}{100}\right)^{4}-\left(\frac{\theta_{2}+273}{100}\right)^{4}\right]}{\theta_{1}-\theta_{2}}
$$

where:

$C_{1-2}$ - radiation heat constant surfaces air layer 1 and $2, \mathrm{~W} /\left(\mathrm{m}^{2} \mathrm{~K}^{4}\right)$,

$\theta_{1}, \theta_{2}$ - temperature surfaces air layer 1 and $2, \mathrm{~K}$

This relation was used to calculate how the value of the coefficient $h_{r}$ (the designation $h_{r(1-2)}=h_{r}$ has been applied hereinafter) depends on the temperature of surfaces creating an unventilated air layer. Assuming the emissivity of both surfaces at the level of $\varepsilon=0.9$, the value of the coefficient $h_{r}$ was determined for three cases; temperature of the warmer surface: $19^{\circ} \mathrm{C}$ - which may correspond to the location of an air void in an external wall on the side of the interior; $9^{\circ} \mathrm{C}$ - example location of an air void in the middle of an envelope; $0^{\circ} \mathrm{C}$ - location of a void on the side of the exterior (Table 2).

The comparison of data in Table 2 shows that the value of the coefficient $h_{r}$ decreases along with the increase of the temperature difference between the surfaces creating an air void. There is also a noticeable reduction in the value of the coefficient $h_{r}$ along with the temperature drop on the surfaces of the air layer. This translates to an increase in the thermal resistance of the air layer, resulting from the phenomenon of thermal radiation between two surfaces creating an unventilated air layer.

The value of the coefficient $h_{r}$ was also determined for a case when one of the surfaces limiting the air layer is coated with a low-emissivity material, such as aluminium foil. Three values of the radiation heat constant $C$ were assumed: $0.2 ; 0.4 ; 0.6$. Calculations were performed for a case of location of an air layer on the warmer side of an external wall (for $\theta_{l}=19^{\circ} \mathrm{C}$ ), and in the second case, assuming location of the void on the cold side of the envelope (for $\theta_{l}=0^{\circ} \mathrm{C}$ ). The results were compared in the chart (Fig. 2). 
Table 2. Value of the radiation heat transfer coefficient $h_{r}$ by depending on the temperature value $\theta_{l}$ and temperature difference on the air layer surfaces $\Delta T$.

\begin{tabular}{|c|c|c|c|}
\hline \multirow{2}{*}{$\begin{array}{c}\text { Temperature } \\
\text { difference, } \boldsymbol{\Delta} \boldsymbol{T}\end{array}$} & \multicolumn{3}{|c|}{ Value of the radiation heat transfer coefficient $h_{r}$ by depending } \\
\hline \multirow{2}{*}{$\mathbf{K}$} & $\mathbf{0}^{\circ} \mathbf{C}$ & \multicolumn{3}{|c|}{$\mathbf{9}^{\circ} \mathbf{C}$} & $\mathbf{1 9}^{\circ} \mathbf{C}$ \\
\hline 1 & & \multicolumn{3}{|c|}{$\mathbf{W}\left(\mathbf{m}^{2} \mathbf{K}\right)$} \\
\hline 2 & 3.76 & 4.15 & 4.60 \\
\hline 3 & 3.74 & 4.12 & 4.58 \\
\hline 4 & 3.72 & 4.10 & 4.55 \\
\hline 5 & 3.70 & 4.08 & 4.53 \\
\hline 6 & 3.68 & 4.03 & 4.51 \\
\hline 7 & 3.66 & 4.04 & 4.49 \\
\hline 8 & 3.64 & 4.01 & 4.46 \\
\hline 9 & 3.62 & 3.99 & 4.44 \\
\hline 10 & 3.60 & 3.97 & 4.42 \\
\hline
\end{tabular}

The comparison shows that the reduction of radiation heat constant (emissivity) of one of the surfaces of the air void, as well as the drop of the surface temperature, result in significant reduction of the value of the coefficient $h_{r}$, evidencing an increase in a component of thermal resistance of such an envelope, connected with a drop in intensity of radiation heat exchange.

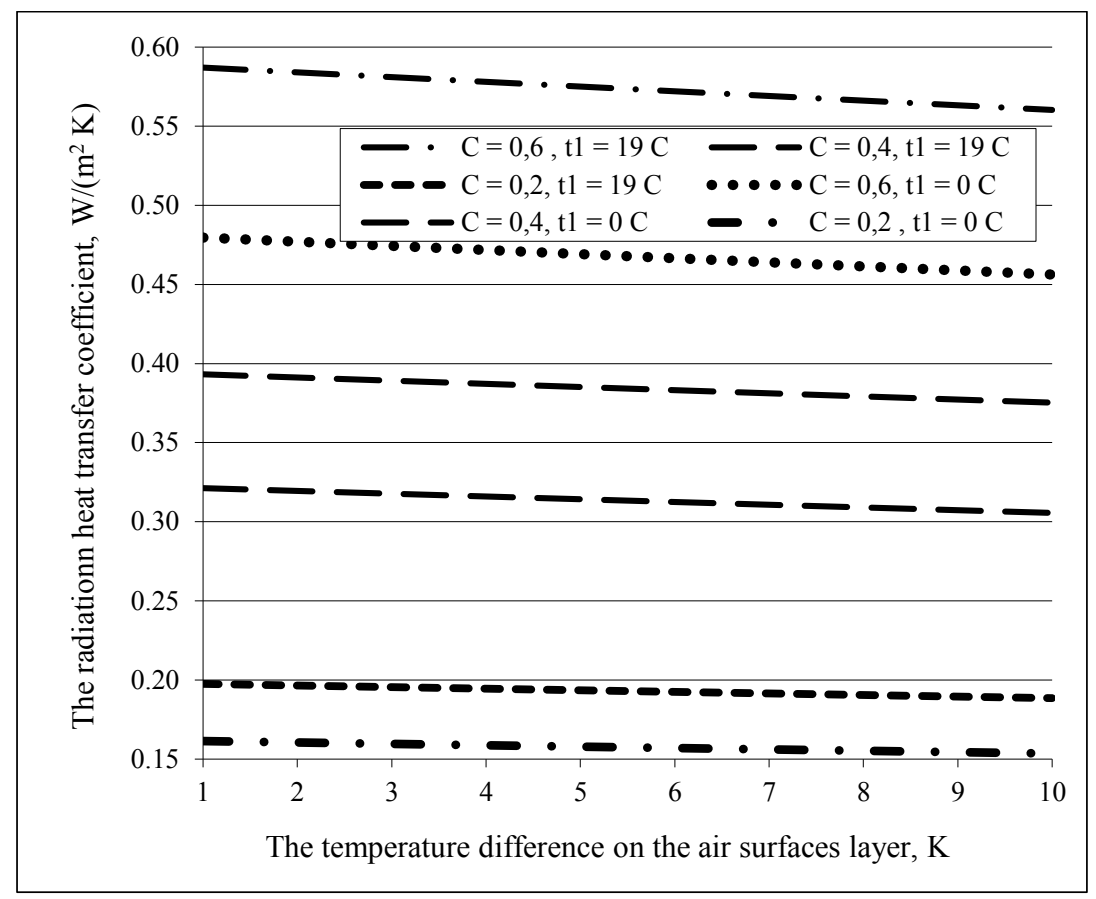

Fig. 2. The nature of the change of value of the radiation heat transfer coefficient $h_{r}$ depending on the temperature difference at the limits of the air layer and radiation heat constant $C$ for a parallel surfaces. 
This also indicates the possibility of considerable reduction of the insulation properties of the envelope in case of loss of the assumed material radiation heat constant level, e.g. as a result of oxidation of the aluminium foil surface over time. This fact requires separate research and appropriate consideration in thermal insulation capacity assessment of external envelopes featuring structural solutions of such kind.

\section{Conclusions}

Investigations, fulfilled by the authors, show that the heat protection properties of closed air gaps depends mush on the thickness of the layer: with increasing thickness from $1 \mathrm{~cm}$ to $7 \mathrm{~cm}$, the thermal resistance of the air gap increases by $0.25 \mathrm{~m}^{2} \mathrm{~K} / \mathrm{W}$ from $0.145 \mathrm{~m}^{2} \mathrm{~K} / \mathrm{W}$ up to $0.17 \mathrm{~m}^{2} \mathrm{~K} / \mathrm{W}$. Also, it should be mentioned that temperature difference has influence on heat protection of air gap: when the thickness of the air gap is $1 \mathrm{~cm}$, the temperature difference between the sides of the air gap practically does not affect its thermal protection. With increasing thickness, the effect of the difference between temperatures on the surfaces of the air gap increases. The reason for this is an increase in convective heat exchange with the growth of the temperature difference between the surfaces of the air gap.

The greatest influence on the thermal protection of the air layers has emissivity surfaces. is exerted by the emissivity of the surfaces. When its value decreases from $\mathrm{C}=0.6 \mathrm{~W} /\left(\mathrm{m}^{2} \mathrm{~K}^{4}\right)$ to $\mathrm{C}=0.2 \mathrm{~W} /\left(\mathrm{m}^{2} \mathrm{~K}^{4}\right)$, the heat protection of the air gap increases by 4 times.

\section{References}

1. R. Wojcik, Insul. 11/12 (2014)

2. K. Patoka, Insul. 9 (2013)

3. D. W. Yarbrough, K. S. Teh, L. Ch. Haw, E. Salleh, S. Mat, M. Y. Sulaiman, J. of Pow. and Ener. Eng. 4 (2016)

4. S. Uvslokk, Ch. Schlemminger, S. Asphaug, Ener. Proc. 132 (2017)

5. PN-EN ISO 6946-2017-10 Building components and building elements. Heat resistance and heat transfer coefficient. Calculation methods (Polish Committee for Standardization, W. 2017)

6. N. Umnyakova, A. Ujma, Insul. 11/12 (2017)

7. GOST R 56734-2015 Buildings and constructions. The calculation of thermal protection of walls with reflective insulation (Standartinform, M. 2016)

8. K. F. Fokin, Building heat engineering of elements of building envelope (ABOK-PRESS, M, 2006)

9. N. P. Umnyakova, Stroitel'naya orbita, 2 (2013)

10. N. P. Umnyakova, Zhilishchnoye stroitel'stvo, 1/2 (2014) 